\title{
Bilingual Education for Ethnic Koreans in China ${ }^{1}$

\author{
Jin Junshu, Gao Mingxia
} \\ Foreign Language School, Yanbian University, China \\ jinjunshu@sina.com, dianagao816@aliyun.com
}

Key words: bilingual education, ethnic Koreans

\begin{abstract}
Bilingual education for Chinese minority nationalities is an organic and important part of Chinese national education. As a part of China's ethnic minority education, bilingual education for ethnic Koreans becomes more and more important because the demand for the talents mastering different languages is expanded. This paper focuses on bilingual education for ethnic Koreans in China, and it firstly reviews the current situation of bilingual education among ethnic Koreans, then tries to provide some suggestions for the reform of the bilingual education teaching system for ethnic Koreans.
\end{abstract}

\section{Introduction}

As a part of China's ethnic minority education, bilingual education for ethnic Koreans has greatly developed in past sixty years, and has aroused the general concern of minority education. The research on bilingual education for ethnic Koreans not only can promote the smooth development of ethnic minority bilingual education and the implementation of communication among all ethnic groups, but also can enrich the studies on bilingual education and make contributions to promote the development of international bilingual education and practice. This paper focuses on the analysis of the current situation and problems of the Korean bilingual education, and discusses the suggestions for reform methods of the bilingual teaching system of ethnic Koreans in China.

\section{Current Situation of Bilingual Education for Ethnic Koreans in China}

Korean bilingual education has experienced a process of continuous improvement, and it has inherited the traditional culture and customs of ethnic Koreans for many years. However, with the rapid development of economy and the demand for talent development, great changes take place in the education in China. A series of problems emerges at the same time.

\subsection{Population Growth Rate is Low and the Number of Schools and Students Greatly Reduced.}

The development of population has a significant influence on the scale, structure and quality of education (Tan, 2015). With the low population growth rate, the number of schools and students greatly reduced. According to the statistics (Li, 2011), Korean bilingual primary and secondary schools decreased by 697 and the number of students reduced by 118462 from 1997 to 2005. In addition, Korean bilingual secondary schools also reduced by 42 and students reduced by 25961 in this period. Therefore, Korean bilingual primary and secondary schools are facing the problems of a significant reduction in the number of schools and students.

\subsection{Teacher Force is Weak and Structure of Teachers Needs to Be Optimized.}

The number of teaching staff is also influenced by the reduction of student numbers as the faculty-student ratio decreases. On one hand, teachers will have more time for preparing lessons and tutoring students with reducing workload, which seems to be an advantage for teaching. However, there are not enough posts for new teachers because the number of teachers' recruitment should be based on the faculty-student radio. Therefore, teachers' age and knowledge structure can 
not be optimized. In addition, it will become more difficult for teachers to update their education ideas without young ones, and it is also not conducive for the long-term development of schools. On the other hand, the turnover rate of teachers is high and the loss of teachers is also serious. According to the statistics on the teachers in Korean bilingual primary schools in Yanbian area (2011), all the teacher numbers in Korean bilingual schools decreased except that in Hunchun City.

Yanbian state government and education departments proposed "Small-sized Class Teaching" model based on the current situation and the needs of quality education. This model can not only alleviate the "laid-off" problem followed by the reduction of student numbers, but also provide a more effective platform for the exchange between teachers and students. In addition, some schools practice the "reassigning" policy, in which some older teachers change to work in some non-teaching positions such as accommodation office, logistics division, etc. This policy also improves the management level of the school.

\subsection{Population Mobility Becomes High, the Number of Left-behind Children Increases and the Korean Bilingual Education outside Yanbian Area is Difficult to Continue}

Since 1990s, a large number of Korean youth left home and worked overseas with the increase of labor export, and more and more pressures are put on schools. Because the proportion of students whose parents works aboard is very high, the impact of "left-behind children" on ethnic education is more and more prominent.

As is known to all, family education plays a very important role in the process of students' growth, and it provides psychological support and emotional comfort for students as well. However, some teachers have to bear the responsibility of family education on the students whose parents work aboard, and it is very difficult for them to balance the roles between teachers and parents.

The students who follow their parents to different places have to enter the local schools. However, it is difficult for them to receive the education in local schools, especially the national culture education. With the lack of language learning environment there, the children cannot continue to receive the bilingual education. As a result, bilingual education for these children loses after they move out of their residence. Therefore, more attention needs to be paid to the continuity of bilingual education and the sustainable development of Korean bilingual education.

\section{Suggestions for the Reform of the Teaching System of Bilingual Education for Ethnic Koreans in China}

\subsection{Encouraging the Combination of Korean Schools and Chinese Schools to Build up an Open and Compatible system of Bilingual Education}

Ethnic Koreans in China have different residential types, such as mixed one, scattered one and concentrated one (Wan, 2012). The differences of residential types lead to the different ecological environment for learning language. Thus, various modes of bilingual education should be chosen according to specific needs. Bilingual education can be explored in mixed areas of Korean-Chinese and Han-Chinese, the separation of Korean schools and Chinese schools could be broken up, and the combination of them should be encouraged.

Besides, these schools should also provide the students with different bilingual education modes, with respecting the wishes of the parents and students. The teaching ability of bilingual teachers should be improved, the bilingual teaching models and curriculum systems should be strengthened, and the high quality bilingual teaching for ethnic Korean students should be provided.

\subsection{Establishing the Model of Bilingual Education with Respecting Multiple Choices}

The attitudes and willingness of minority students on bilingual learning are complex and diverse. Students will choose different language learning models according to their own needs. Even the ethnic Korean students in the same area should have different options based on their different family backgrounds and cross-cultural adaptability. In these schools merging Han and minority nationalities, different combinations of bilingual courses can be chosen by students, in which 
separated classes and mixed classes for Han and minority nationalities are carried out, and the classes for students' stratification are also in placement. Meanwhile, schools should also encourage opening such courses as ethnic culture, art, customs, or language. The stratification and separation system of bilingual education is a major reform of Singapore's bilingual education system, which has been adopted by many countries in the world, and it is an effective learning model to improve the quality of bilingual education.

\subsection{Developing Bilingual Curriculum Standards, and Enriching Bilingual Curriculum Resources}

It is very essential to develop the standard of bilingual curriculum, which is an indispensable part of the formal curriculum system. The curriculum standard of bilingual education includes the standard of mother tongue and the standard of Chinese for ethnic Korean students.

In the current situation of bilingual education, the lack of curriculum resources is a bottleneck to restrict the effect of bilingual education, because there are not sufficient curriculum resources for teachers and students. Bilingual education curriculum resources include in-school ones and out-of-school ones. In-school resources include life experiences, learning styles, teaching strategies, various books and activities in school, etc. Out-of-school resources include local resources, community resources and family resources, etc. Thus, the construction on network resources of bilingual education should be strengthened, and the advantages of network should be utilized, such as the large capacity, fast delivery and supporting autonomous learning, etc. The students should be provided with high-quality teaching videos, reading materials, learning courseware, to make up the lack of bilingual education resources in-school and out-of-school.

\section{Conclusion}

The research of bilingualism and bilingual education is very complex and multidimensional, which requires the joint efforts of theorists and practitioners of differing disciplines for its development. This paper tries to provide the suggestions for the reform of the teaching system of bilingual education for ethnic Koreans, by overviewing the current situation of bilingual education among ethnic Koreans in China. Although there still exists some problems of bilingual education among ethnic Koreans in China, Koran bilingual schools should not only preserve the diversity in cultures but also increase competition among ethnic Korean students who master three or four languages.

\section{Acknowledgment}

This work is supported by " $13^{\text {th }}$ Five-Year" Social Research Project of Education Department of Jilin Province ([2016]No.268) and Higher Education Research Project of Jilin Provincial Association of Higher Education ([2015]No.07)

\section{References}

[1] Guang Li, "A study on Korean Education in Yanbian Area”, Ph.D. dissertation, Jilin University, 2011.

[2] Ming Gang Wan, Liu Haijian, "On Bilingual Education for Minority in China-From Construction of Policies, Laws and Regulations to Transformation of Education and Teaching Model”, Educational Research, vol. 08, pp. 81, 2012.

[3] Ming Tan, "Language Background and Bilingual Education of Scattered Students", Minzu Tribune, vol. 04 , pp. 40, 2015. 